\title{
Evaluation of the effects of the green nanoparticles zinc oxide on monosodium glutamate-induced toxicity in the brain of rats
}

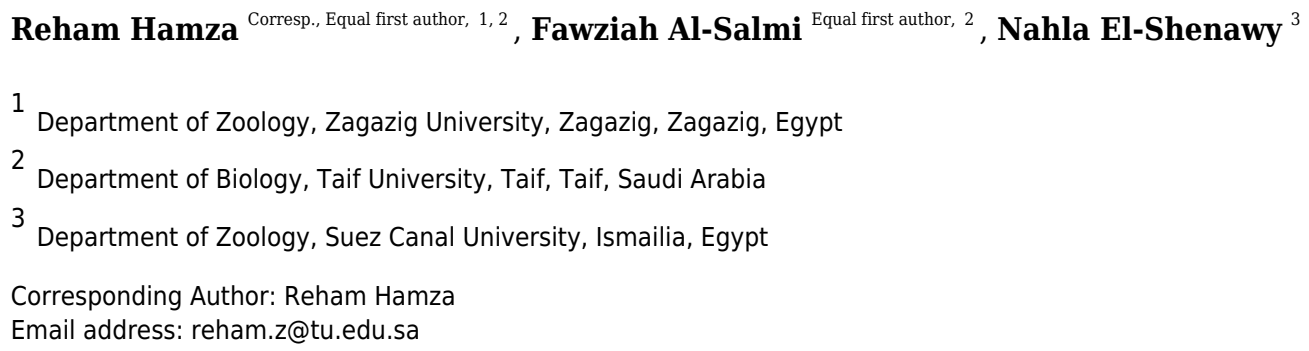

Background: Monosodium glutamate (MSG) is used extensively as a food additive in the diets of many countries around the world. Aim of the study was to determine the effects of green zinc oxide nanoparticles on MSG-induced oxidative damage, neurotransmitter changes, and histopathological alternation in the cerebral cortexes of rats. Methods: MSG was administered orally at two doses of 6 and $17.5 \mathrm{mg} / \mathrm{kg}$ body weight. The higher dose was associated with a significant decline in the activities of superoxide dismutase, catalase, and glutathione peroxidase, as well as the levels of brain-derived neurotrophic factor (BDNF) and glutathione (GSH) in the cerebral cortex of rats. Results: The administration of zinc oxide nanoparticles/green tea extract (ZnO NPs/GTE) to $17.5 \mathrm{mg} / \mathrm{kg}$ MSG-treated rats was associated with significant improvements in all parameters previously shown to be altered by MSG. The higher dose of MSG induced significant histopathological variation in brain tissue. Co-treatment of rats with ZnO NPs/GTE and MSG-HD inhibited the reduction of neurotransmitters and acetylcholinesterase by MSG.

Conclusions: ZnO NPs/GTE have the potential to protect against oxidative stress and neuronal necrosis induced by MSG-HD. ZnO NPS/GTE conferred a greater benefit than the control treatment or ZnO NPs or GTE administered separately. 
1 Evaluation of the effects of the Zinc Oxide/Green Tea Nanoparticles on Monosodium 2 Glutamate-Induced Toxicity in the brain of Rats

3 Reham Z. Hamza ${ }^{1,2}$, Fawziah A. Al-Salmi ${ }^{1}$, Nahla S. El-Shenawy ${ }^{3 *}$

$4{ }^{1}$ Biology Department, Faculty of Science, Taif University, Taif 888, Saudi Arabia

5 2Zoology Department, Faculty of Science, Zagazig University, Zagazig 44519, Egypt

6 3Zoology Department, Faculty of Science, Suez Canal University, Ismailia, 41522, Egypt

7

\section{Abstract}

9 Background: Monosodium glutamate (MSG) is extensively used as a supplement in diets of a lot of countries of the world. The aim of the study: The research was to figure out the effects of zinc oxide/green tea nanoparticles on MSG-induced oxidative damage, neurotransmitters changes and histopathological alteration in the cerebral cortex of the rats. Methods: MSG administered at two doses orally of 6 (MSG-LD) and $17.5 \mathrm{mg} / \mathrm{kg}$ (MSG-HD) body weight for successive 30 days, whereas the higher dose significantly declined the activities of superoxide dismutase, catalase, the glutathione peroxidase as well as, the levels of brain-derived neurotrophic factor (BDNF), glutathione $(\mathrm{GSH})$ in the cerebral cortex of rats. Results: The administration of Zinc oxide nanoparticles / green tea (ZnO NPs /GTE) to $17.5 \mathrm{mg} / \mathrm{kg}$ MSGtreated rats was significantly improved all previous parameters changed induced by MSG. The higher dose of MSG was significantly induced histopathological variation in the brain tissue. Cotreatment of rats with ZnO NPs /GTE and MSG-HD inhibited the reduction of neurotransmitters and acetylcholinesterase by MSG. Conclusions: ZnO NPs /GTE have protective potential versus the oxidative stress and neuronal necrosis induced by MSG-HD. ZnO NPs /GTE consider more benefit as compared with the control animals or ZnO NPs or GTE separately.

Keywords: Zinc oxide nanoparticles; Green synthesis, Monosodium glutamate , Brain, Neurotransmitters, Brain biomarkers, Cyclooxygenase-2, Acetylcholinesterase, Histopathology. Abbreviations: MSG: Monosodium glutamate ; ZnoNPs : Zinc oxide nanoparticles ; GTE : Green tea extract ; MSG-HD: Monosodium glutamate (High dose) ; MSG-LD: Monosodium glutamate (Low dose); BDNF: brain-derived neurotrophic factor ; GSH: glutathione; $\mathrm{Ti}_{2} \mathrm{O}$ :Titanium oxide, $\mathrm{CuO}$ : Copper oxide; MPO: Myeloperoxidase ; XO: Xanthine oxidase .

\section{*Corresponding authors:}

RZ. Hamza, Assist. Prof. of Physiology, Zoology Department, Faculty of Science, Zagazig University, Zagazig 44519, Egypt. 
-Assist.Prof.of Physiology, Biology Department, Faculty of Science, Taif University, Taif 888, Saudi Arabia.

Email: dr_reham_z@yahoo.com. Tel:00201154200862.

\section{Introduction}

Metal oxide nanostructures are one of the most extensively fabricated types of nanomaterials [1]. There are many forms of mineral metal oxides have been synthesized and continue to exist as $\mathrm{TiO}_{2}, \mathrm{CuO}$, and $\mathrm{ZnO}$. Zinc oxide nanoparticles ( $\mathrm{ZnO} \mathrm{NPs}$ ) are of maximum attentiveness because they are low-cost to produce, safety makes $\mathrm{ZnO}$ a good candidate for use in food preservation and can be formed efficiently. ZnO NPs have extensive application in artificial flavoring [2], cosmetics, sunscreens, and batteries [3]. Also, the biological applications of $\mathrm{ZnO} \mathrm{NPs}$ have a great role in the biosensor and medical devices. $\mathrm{ZnO} \mathrm{NP}$ has anticancer effects [4], antibacterial activity [5], agriculture, and biomedicine applications [6]. There was a concept that $\mathrm{ZnO}$ NPs can be applied to some of biomedical materials [7].

However, Afifi et al. [8] found $\mathrm{ZnO}$ NPs had the restorative effect on male reproducing functions. It had adverse effects on animals and human health because the size of the NPs surface area greatly augments their capability to produce ROS through oxidative stress [9]. It has the excessive potential to pass through the placenta and testis barriers to efficient targeting of cells and causing many diseases [10]. Therefore, it is obligatory to evaluate its toxicity of $\mathrm{ZnO}$ NPs in distinctive organs for long- and the short-period of study. Recently, the effects of $\mathrm{ZnO}$ NPs on the liver and renal tissues had been evaluated in the laboratory [10-12].

Moreover, biosynthesis of nanoparticles using microorganisms and plants had biomedical applications [13]. They allow the synthesis of ZnO NPs with the great purities and show more activity. Using extracts of any parts of the plant is a very safe to the ecological environment, cheap in its preparation and it does not use any transitional groups. It takes very short-time and produces a pure product free of any contaminants [14]. For example, spherical shaped ZnO NPs were created by Aloe Vera leaf extract where the active groups of plant extract acted as both reducing and eclipse agent. Santhoshkumar et al. [15] found that ZnO NPs using plant leaf extract (P. caerulea L.) can be worked against the urinary tract infections [16].

In spite of the fact that the NPs biosynthesis by different plant extracts is vague, it has been showed that the biomolecules in plant extract (protein, phenol, and flavonoids) play a 
65

66

67

68

69

70

71

noteworthy part within the diminishment of metals particles and eclipsing the biosynthesized nanoparticles [17].

Green tea (Camellia sinensis) is one of the foremost expanded drink around the world[18]. It is investigated to have profitable effects on wellbeing due to his high fulfilled of polyphenols as epigallocatechin-3-gallate (EGCG), which has anti-oxidative properties [19] and repress the reactive oxygen species (ROS) activity in a dose-dependent way. Polyphenols erected from the green tea appear 20 times more impressive antioxidant activity than vitamin $C[16,20]$. Abshenas et al. [21] reported that the green tea extract could reduce the conflicting effects of hyperthermia on semen parameters in a short duration.

Based on previous studies, MSG has a toxic effect on the brain by increasing the level of neurotransmitter of the nervous system of mammals which play an essential role in both physiological and pathological processes [22]. Also, it increased in intracellular calcium which in turn promotes a arrangement of enzymatic response which leads to cell death. Besides, it has been appeared that MSG utilization causes obsessive changes in brain structure related with neuronal damage and articulated oxidation stress [23]. MSG overdose has been shown to induce neurodegenerative injuries, Parkinson's disease, and epilepsy [24]. It is known to stimulate the discharge of norepinephrine (NE) and dopamine (DA) from a number of different brain regions $[25]$.

Serotonin, or 5 hydroxytryptamine (5HT), could be a biogenic amine affecting numerous functions of the central nervous system. It is stored in vesicles and released into the blood plasma as a response to certain stimuli [26]. Expanded brain serotonin level is recommended to enhance the cognitive performance. However, a decline in brain 5HT and its precursor tryptophan contents has been appeared to destroy memory ability [27].

It has been entrenched that a number of bioactive markers participate in neuropathic pain, such as cyclooxygenase -2 (COX-2), and prostaglandin E2 (PGE2) [28]. BDNF is the richest neurotrophin in the brain and fundamental for neuronal survival during the development of brain's neurons [29]. BDNF is also disclosed in the liver [30], skeletal muscle [31] and cardiovascular system [32]. Cyclooxygenase (COX) is responsible for prostaglandin (PG) $\mathrm{H}$ formation by synthesis of prostanoids of arachidonic acid metabolites forming PGs, prostacyclin, and thromboxanes [33]. COX-2 is asserted in many cell types as the effect of growth factors, cytokines, and pro-inflammatory variables. 
96

97

98

99

100

101

102

103

104

105

106

107

108

109

110

111

112

113

114

115

116

117

118

119

120

121

122

123

124

125

The role of ZnO NPs /GTE against MSG toxicity on the brain has not studied until date, except on the liver. In the ongoing study, It was assessed to study the neuroprotective effect of ZnO NPs /GTE against MSG neurotoxicity. The effect of ZnO NPs /GTE on brain rats was evaluated on the bases of assessment of some neurotransmitters, redox status assays, and histopathology changes.

2. Experimental procedure

\subsection{Zinc oxide nanoparticles $\left(\mathrm{Zn}_{0} \mathrm{NPs}\right)$ properties and chemicals}

The $\mathrm{ZnO}$ nanoparticles are a white powder with $200 \mathrm{~nm}$ diameter, 20-40 nm size, and purity $99.5 \%$ (Sigma-Aldrich Company). The morphology and particle size of ZnO NPs were characterized using scanning electron microscopy (SEM, JSM-6301, Japan) [10] and Energy Dispersive X-Ray Diffractive, EDX, respectively.

\subsection{Preparation of green tea extract, MSG and green ZnO NP complex}

The green tea extract (GTE) was processed as described before by Zanch et al. [11]. The stock solution of MSG was provided by dissolving $60 \mathrm{~g}$ in $1000 \mathrm{~mL}$ of distilled water. The process of the GTE conjugation with ZnO NPs was explained previously in our laboratory [10].

\subsection{Animals and ethical consideration}

In this study, adult male rats weighed 200-250 g were used. They were purchased from the Faculty of Pharmacy (Zagazig University, Egypt). They were used after two weeks of the acclimatization. The animals were housed beneath the ordinary circumstances of temperature $\left(23^{\circ} \mathrm{C}\right)$ and were given drinking tap water and rodent nourishment pellet. The rats were chosen as the foremost appropriate animal species for the experiment as they are small, easily housed and maintained, and adapt well to new surroundings, easy to handle, they are mimic human greatly , so we can test these parameters effectively.

The sample size of rats was chosen based on the less number of animals to get actual results.

This experimental study was performed with the confirmation of the local ethics committee on use and care for animal experiments at Taif University of Biological Department (permit number: 39-31-0034). 


\subsection{Experimental protocol}

There were eight groups ( $\mathrm{n}=8$ each) that were treated as the following; vehicle (for control), ZnO NPs (10 mg/kg), GTE (250 mg/Kg), and GTE / ZnO NPs complex as mentioned in groups two and three. The other four groups were treated with the lower dose of MSG (6 $\mathrm{mg} / \mathrm{Kg})$, the higher dose of MSG (17.5 mg/Kg), MSG-LD + GTE / ZnO NPs complex and MSGHD + GTE / ZnO NPs complex. All the different treatment was given to the rats orally by feeding needle. The rats were sudden decapitation and brain was removed for more evaluation after 30 days of treatment.

\subsection{Acetylcholinesterase estimation}

137 The blood samples were collected from the retro-orbital plexus vein and were centrifuged at 3,000 $\mathrm{xg}$ for $15 \mathrm{~min}$. Serum was collected and frozen at $-20{ }^{\circ} \mathrm{C}$ until the biochemical estimation. Acetylcholinesterase (AChE) in the serum was estimated by the kit of Bio-diagnostic Company, Dokki, Giza, Egypt, according to Magnotti et al. [33].

\subsection{Brain preparation and estimation of neurotransmitters}

Rats were killed by sudden beheading after 30 days of treatment. The brain was quickly and carefully dissected on dry ice glass plate between 8.00 and 9.00 a.m for all the groups and was reserved in a freezer at $-20^{\circ} \mathrm{C}$. The brain tissues were cut coronal to get the cerebral cortex. The brain samples were split into two parcels, the primary one was utilized for the planning of brain homogenates and the second was urilized for histological examination.

The first set of the cerebral cortex was weighed and homogenized in a cold acidified nbutanol to obtain $10 \%$ homogenate. The internal standard of serotonin, norepinephrine, and dopamine was prepared by adding $0.3 \mathrm{~mL}$ standard mixture $(100 \mu \mathrm{L}$ containing $100 \mu \mathrm{g}$ of each neurotransmitter) to $9.7 \mathrm{~mL}$ of $0.2 \mathrm{~N}$ acetic acid. Aliquots of $200 \mu \mathrm{L}$ of this solution were diluted to $300 \mu \mathrm{L}$ with $0.2 \mathrm{~N}$ acetic acid then, $3 \mathrm{~mL}$ of acidified $\mathrm{n}$-butanol was added $(0.85 \mathrm{~mL}$ of concentrated $\mathrm{HCl} / \mathrm{L} \mathrm{n}$-butanol) and internal standard tubes were centrifuged at $10000 \mathrm{xg}$ for 5 min. The aqueous phase was collected and divided into two portions; the first one was used for serotonin determination while the other was used for epinephrine, norepinephrine, and dopamine assessment. 
156

157

158

159

160

161

162

163

164

165

166

167

168

169

170

171

172

173

174

175

176

177

178

179

180

181

182

183

184

185

186

Serotonin content was carried out depending on the reaction of ortho-phthalaldehyde [34] and according to the instructions of the manufacturer of ELISA kits. The epinephrine, norepinephrine, and dopamine estimated by the method of Ciarlone [34] that depend on the oxidation by iodine that consists of acetic acid $(5 \mathrm{~N})$, alcoholic iodine solution $(0.1 \mathrm{~N})$, disodium ethylene diamine tetra-acetic acid dehydrate $(0.1 \mathrm{~N})$ in sodium acetate $(\mathrm{pH}$ 6.7-7) and alkaline sulfite $(5 \mathrm{~N})$ that prepared just before use.

\subsection{Determination of redox status of the brain}

The superoxide dismutase (SOD) activity was evaluated using the assay kit and was presented as $\mathrm{U} / \mathrm{g}$. Catalase (CAT) activity was measured according to an assay kit and was expressed as mmol/g tissue. All the kits brought from Bio-Diagnostic Company CO. Giza, Egypt.

Glutathione (GSH) level and glutathione peroxidase (GPx) activity were determined using the method of the commercial kit from Bio-Diagnostic.

Myeloperoxidase (MPO) activity was measured by Suzuki et al. [35]. Xanthine oxidase (XO) activity was assayed spectrophotometrically according to Litwack et al. [36].

Total thiols level was dogged by the method of $\mathrm{Hu}$ [37] and was presented as mmol/g tissue.

\subsection{Estimation of some bioactive compounds markers for neuroinflammation}

The cerebral cortex levels of BDNF, COX-2 and PGE2 in supernatant (cerebral cortex was homogenized in two fold volumes of $0.01 \mathrm{~mol} / \mathrm{L}$ phosphate-buffered saline that containing $0.05 \%$ Tween- 80 and centrifugation at $15,000 \mathrm{~g}$ at $4{ }^{\circ} \mathrm{C}$ for $20 \mathrm{~min}$ ) were measured by (ELISA) with monoclonal antibodies particular for rats BDNF, COX-2, and PGE2. The commercial ELISA kit of rat BDNF was acquired from WKEA Co. The ELISA kit of rat COX-2 and PGE2 were purchased from Immuno-Biological Laboratories Co, USA.

\subsection{Sample preparation for light microscopy and histopathological analysis}

At the end of the experimental time, the second set of the cerebral cortex was fixed in 10 $\%$ formal saline, dehydrated in a graded series of ethanol and finally, embedded in paraffin. The 
187 188 189

190

191

192

193

194

195

196

197

198

199

200

201

202

203

204

205

206

207

208

209

210

211

212

213

214

215

216

samples were sectioned by microtome into $3-4 \mu \mathrm{m}$ thickness and stained with hematoxylin and eosin (H\&E) for histopathological examinations employig a light microscope.

\subsection{Statistical analysis}

The data were analyzed by using the SPSS software, version 20. Statistical significance between groups was computed by investigation of variance and analyzed by One-way ANOVA and Tukey's test. The contrasts were plan to be significant at $\mathrm{P} \leq 0.05$.

\section{Results}

\subsection{Structural and morphological characterization}

The SEM image of the sample is shown in Fig. 1a. The particles can be observed as spherical or quasi-spherical particles are dominant. The chemical compositions of the zinc oxide/green tea complex were determined using EDX (Fig. 1b). The study was carried out for the synthesized ZnO NPs complex with GTE to know the complex elemental composition. The peaks of the two essential elements like carbon and oxygen, and respective $\mathrm{Zn}(\mathrm{II})$ elements, which constitute the molecules of ZnO NPs/GTE complex is clearly identified as shown in Fig. $1 \mathrm{~b}$ and this analysis showed the peaks that corresponded to the optical absorption of the $\mathrm{ZnO}$ NPs/GTE complex. The elemental analysis of the complex yielded $40.77 \%$ of zinc, $30.18 \%$ of oxygen and $29.05 \%$ of carbon which proves that the produced ZnO NPs complex with GTE is in its highest purified formula and confirmed it's a combination.

\subsection{Hormones, AchE and thiol levels}

Effect of ZnO NPs / GTE mixture on the dopamine, serotonin, catecholamine, acetylcholinesterase, and thiol were presented in Table 1. Significant declined in catecholamine level (noradrenaline and adrenaline), dopamine, and serotonin was detected in the higher dose of MSG in comparing with normal animals. In addition to neurotransmitters, significant differences were also detected in the activity of AchE and thiol levels at the $17.5 \mathrm{mg} / \mathrm{kg} \mathrm{MSG}$ as compared with the control animals (Table 1). There were not any differences between ZnO NPs or GTE 
217 groups and control rats. In the case of the treatment the animals with $\mathrm{ZnO}$ NPs/GTE mixture and

218 MSG, the values of all the previous parameters returned back approximately to the control group.

219

220

\subsection{Antioxidant and oxidative stress enzymatic/non-enzymatic}

221

222

The SOD activity was significantly decreased in MSG-HD and ZnO NPs groups (Fig. 2).

However, CAT activity decrease only in MSG-HD treated animals and did not change in all

223

224

225

226

227

228

229

230

231

232

233

234

235

236

237

238

239

240

241

242

243

244

245

246 other groups (Fig. 2).

Treatment the rats with MSG at different doses (6 and $17.5 \mathrm{mg} / \mathrm{kg}$ ) caused a significant decrease in GPx activity and GSH level at the higher dose only (Fig. 3). ZnO NPs only or with MSG at different doses significantly decreased the GSH and GPx of the brain rats.

No critical changes were noticed in MPO of all treated group except the MSG-HD with ZnO NPs/ GTE animals (Fig. 4). XO activities were elevated in ZnO NPs as compared to control group by 1.9-fold, as well as in MSG-LD or MSG-HD with ZnO NPs / GTE as compared to its relative group of MSG by 1.5- and 1.7-fold, respectively (Fig. 3).

The level of BDNF was decreased significantly in ZnO NPs- treated animals by $41.5 \%$ as compared to normal rats (Fig. 5). In both treatment doses of MSG with ZnO NPs / GTE, the BDNF was significantly decreased at the lower dose and increased at the higher dose.

In MSG-HD group, the COX-2 activity elevated by 2.1- fold as compared to control (Fig. 6). In the $\mathrm{ZnO}$ NPs group, the COX-2 activity decreased by $33 \%$ as compared to normal animals. The combination of MSG-HD with ZnO NPs /GTE caused decreased in COX-2 by $40 \%$ as compared to MSG-HD-treated rats.

The PGE2 level was increased by 1.8 -fold in MSG-HD group as compared to control animals (Fig. 7). The MSG-LD with ZnO NPs / GTE increased the PGE2 by 1.3 -fold as compared to MSG-LD group. However, The MSG-HD with ZnO NPs / GTE decreased PGE2 by $24 \%$ as compared to MSG-HD animals.

\subsection{Histological Changes}

Histopathological assessment of brain tissues revealed that no histopathological alternations were observed in control or ZnO NPs or GTE groups. All these groups of rat showed the normal arrangement of layers of neurons and neuronal fibers (Fig. 8A, 8B and 8C) and the 
247 normal cerebral cortex shaped of circular and pyramidal neurons encompassed by eosinophilic 248 glial filament were also watched.

249 The cross-section of the rat brain treated with ZnONPs/GTE $(10 \mathrm{mg} / \mathrm{Kg})$ showed a 250 normal white matter with normal neurons and neuronal fibers (Fig. 8D). The moderate area of 251 hemorrhage and necrosis in the brain of rats treated with MSG-LD (Fig. 8E). However, the brain 252 tissue of the rats that treated with MSG-HD showed a large area of hemorrhage and necrotic 253 areas of the brain with the congested area, in addition, degeneration in some glial cells was 254 noticed (Fig. 8F).

255 The lower dose of MSG and Zn ONPs/GTE reported having a very reduced the congested 256 area with normal neural fibers (Fig. 8G). The highest dose of MSG and ZnONPs/GTE showed 257 the recovery of the congested area with the moderate area of necrosis with normal appearance to 258 fibers and reduced necrotic neurons (Fig. 8H).

\section{Discussion}

In the present study, the brain has been selected because it is more insightful to the oxidative stress as it contains the low concentration of antioxidants, and it needs high energy as well as it contains the high cellular levels of lipids and proteins. The microglial actuation produces high contents of free radicals that can harm the proteins, lipids, as well as the nucleic acids at the particle deposition location [38].

MSG-induced oxidative stress pathways in cerebral cortex could be by decreasing the neurotransmitters as shown in the present investigation where the levels of dopamine, serotonin, epinephrine, and norepinephrine were reduced with $17.5 \mathrm{mg} / \mathrm{kg}$ of MSG. The prolonged use of MSG-induced histopathological changes in the brain depending on the dose and the ROS formation which confirmed by declining the antioxidant enzymes activities of SOD, CAT, GPx, and reduces the level of GSH as well as the BDNF. However, the levels of COX-2 and PGE2 were significantly elevated in the cerebral cortex as the MSG-treatment.

The present study committed by other previous investigations, long-term treatment of MSG is correlated with several reversals in the nervous system [39-40), liver and kidneys [11,41] due to an elevation of ROS production [42]. 
279 to mice elevated the malondialdehyde and diminished the GSH levels in brain tissue. Similar 280 diversity within the antioxidant enzymes activities combining ingestion of MSG was reported 281 already in the heart tissue of rats by Singh and Ahluwalia [31] and liver tissue by EL-Salmi et al. $282[10]$ as well as in the kidney tissue [44-45]. This is often an sign that the noxious impact of MSG extends to all tissues within the body. Free radicals assembled within the brain tissue due to ingestion of MSG are known to cause disintegration of most proteins including enzymes [42]. The defect in blood-brain barriers and compete in the deleterious action on the brain antioxidant enzymes and other biomarkers occurred as the free radicals formation in situ and also due to its diffusion from circulation.

Dopamine which is a neurotransmitter that occur abundantly in the central nervous system [46]. Catecholamine is of core importance getting learning skills and also in the building the memory [47]. Moreover, alterations of serotonin levels may be correlated with defect the learning and remembrance consolidation [48]. In the current study, only the animals exposed to MSG-HD displayed a significant decline in the levels of the neurotransmitter (Dopamine, serotonin, epinephrine, and norepinephrine) of the brain tissue. This observation showed that the MSG-induced toxicity through the impairment of the neurotransmitters as Hashem et al. [49] found that MSG changed the neurons and astrocytes in the cerebellar cortex of albino rats. Therefore, the present data indicated that the neurotransmitters are involved in protecting the brain from MSG-HD toxicity.

The catecholamine level was diminished as the dosage of MSG was elevated. Kardeşler and Başkale [50] reported that the reduction in the catecholamine level empathized to the increment the MSG dosage that is a neurochemical reasoning for the learning disorderliness. Also, Tao et al. [51] found that MSG injections caused changes in the brain's hippocampus part which may result in a few behavioral alternations in the animals.

Madrigal et al. [52]reported that COX-2 has some important brain functions as a synaptic activity, remembrance consolidation, functional hyperemia, and neuro-inflammation. The COX2 level was increased significantly as the effect of MSG-HD that was a confirmation of a candid importance of COX-2 in neurodegenerative functions. The elevation of COX-2 in MSG-HD animals was confirmed by the histopathological changes as neurons are especially vulnerable to 308 harm caused by free radicals creation through COX-2 peroxidase activity, whereas glial cells are 
309

310

311

312

313

314

315

316

317

318

319

320

321

322

323

324

325

326

327

328

329

330

331

332

333

334

335

336

337

338

more defiant [52]. They also found that inhibition of COX-2 decreasing the membrane lipid peroxidation mediators and the decline of GSH strongly suggested that the COX isoform is elaborated in the aggregation of oxidative mediators erect in the brain.

Over-production of COX-2 has been correlated with neurotoxicity in hypoxia/ischemia and seizures [32]. Increasing the activity of COX-2 led to the formation of PGE2 that could be participated to synaptic malleability over different mechanisms, including inflection of adrenergic, noradrenergic, and glutamatergic neurotransmission, reshaping the actin in the cytoskeleton thus changing the shape of spines and dendrites, and controls the membrane excitability [53]. Considerable mechanisms could be provoked by COX-2 overproduction that could commit to oxidative stress-mediated harm by generating ROS during the peroxidase activity. Moreover, PGE2 has reinforced the effect of glutamate release. It could lead to the producing of more reactive free radical such as peroxynitrite. COX-2 expression within the brain has been related with pro-inflammatory activities, thought to be instrumental in neurodegenerative forms.

$\mathrm{ZnO}$ NPs inhibited the activity of COX-2 as compared to the control that could have beneficial to decline the inflammation and degenerative neuropathology.

There were not any histopathological changes in the ZnO NPs treatment-rats as comparing with normal animals. These results are consistent with Wang et al. [54] and Zheng et al. [55] who confirmed that ZnO NPs do not have any toxic effects on the brain tissues. In the contrasting context, Win-Shwe and Fujimaki [56] who reported that the toxic effects of ZnO NP on the CNS include cytotoxicity, inflammation, and oxidative stress induction that result in neurodegeneration. Granted and Anreddy [57] found that $5 \mathrm{mg} / \mathrm{kg} \mathrm{ZnO} \mathrm{NPs} \mathrm{did} \mathrm{not} \mathrm{produce} \mathrm{any}$ significant alternations in histology of the brain of rats after a month of the treatment.

However, Elshama et al. [58] found that ZnO NPs led to the degeneration of the brain and spinal cord including pyramidal and glial cells, white and gray matter related with pyknotic nuclei and disturbance in many cytoplasmic organelles as well as changes in ultrastructural of the brain and spinal cord depending on its dose. The present study differed from the observations of Elshama et al. [58] in the effect of ZnO NPs could be due to the difference in the dose, route and the duration of exposure. Histopathological examination of rat brain exposed to $\mathrm{ZnO}$ NPs showed normal structure as the control animals. 
There were no data available in the literature about the effect of ZnO NPs / GTE mixture

340

341

342

343

344

345

346

347

348

349

350

351

352

353

354

355

356

357

358

359

360

361

362

363

364

365

366

367

368

369

on the brain. The mixture has increased the activities of SOD, CAT, GPx, and levels of GSH, and BDNF of the brain tissue than that the effect of ZnO NPs or GTE separately. Also, it has the ability to reduced MPO and XO than the ZnO NPs.

The action of Zn ONPs/GTE on MSG-induced brain toxicity can be due to its role on various neurotransmitters or due to its antioxidant property as the CAT, SOD, GPx and GSH enhanced as well as restored the other neural biomarkers parameters. This indicates that the mixture can decrease the harm caused by the induction of MSG-HD. This effect is attributable to the antioxidant character of the mixture which helps to scavenge free radicals thus prevent the tissues from damage.

Treating the rats with $\mathrm{ZnO}$ NPs/ GTE mixture decreased the COX-2 activity in MSG-HD group that directly decreased the level of BDNF in the brain tissue.

The histopathological examination of the brain of rats treated with different dosages of MSG showed marked changes in the tissue with MSG-HD only. Severe damage occurred in the brain cell of rats that represented in focal gliosis, cellular edema, focal hemorrhage, and necrosis. Such changes also go in parallel with biomarkers changes represented in the activities of the brain antioxidant enzymes (SOD, CAT, GPx, MPO, XO, AChE, and COX-2) and levels of BDNF and PGE2. However, this improvement was not complete. A few pathological injuries still hold on but to less degree in MSG-HD with ZnO NPs/ GTE.

\section{Conclusions}

In conclusion, MSG suspiciously affects the neurotransmitters of rats as well as to its effects on biomarkers of the brain parameters such as BDNF, COX-2 and PGE2 and antioxidant enzymes activities (SOD, CAT, and GPx). MSG caused neuronal degeneration in the cerebral cortex that supported those findings alternation in neurochemical biomarkers. The results of COX-2 revealed that it is one of the mechanisms through which stress may lead to cellular oxidative status in the brain by MSG-HD. Therefore, ZnO NPs/ GTE proved to be benefit in decreasing the toxicity of MSG and ZnO NPs due to its conjugation with GTE. Its ameliorated action could be related to its ability to remove the free radical.

\section{References}


370

371

372

373

374

375

376

377

378

379

380

381

382

383

384

385

386

387

388

389

390

391

392

393

394

395

396

397

398

399

400

1. Chen Q, Luo Y, Kuang S, Yang Y, Tian X, Ma J, Mai S, Xue L, Yang J (2017) Cyclooxygenase-2 signaling pathway in the cortex is involved in the pathophysiological mechanisms in the rat model of depression. Sci Rep 28;7(1):488. doi: 10.1038/s41598-01700609-7.

2. Catherine CB, Adam SG, Curtis G (2003) Functionalization of magnetic nanoparticles for applications in biomedicine. J Phys D: A ppl Phys 36:198-207.

3. Ma H, Williams PL, Diamond SA (2013) Ecotoxicity of manufactured ZnO nanoparticles: A review. Environ Poll 172: 76-85.

4. Wahab R, Dwivedi S, Umar A, Singh S, Hwang IH, Shin HS, et al. (2013) ZnO nanoparticles induce oxidative stress in Cloudman S91 melanoma cancer cells. J Biomed Nanotechnol 9: 441-449.

5. Dwivedi S, Wahab R, Khan F, Mishra YK, Musarrat J, Alkhedhairy AA (2014) Reactive oxygen species-mediated bacterial biofilm inhibition via zinc oxide nanoparticles and their statistical determination. Plos One 9: e111289-e111289.

6. Sirelkhatim A, Mahmud S, Seeni A, Kaus NHM, Ann LC, Bakhori SKM, et al. (2015) Review on zinc oxide nanoparticles: antibacterial activity and toxicity mechanism. Nano-Micro Lett 7: 219-242.

7. Berube DM (2008) Rhetorical Gamesmanship in the Nano Debates over sunscreens and nanoparticles. J Nanopar Res 10: 23-37.

8. Afifi M, Almaghrabi OA, Kadasa1 NM (2015) Ameliorative effect of zinc oxide nanoparticles on antioxidants and sperm characteristics in streptozotocin-induced diabetic rat testes. Biomed Res. Intern. Volume 2015, Article ID 153573, 6 pages http://dx.doi.org/10.1155/2015/153573

9. Moller P, Jacobsen NR, Folkmann JK, Danielsen PH, Mikkelsen L, Hemmingsen JG, Vesterdal LK, Forchhammer L, Wallin H, Loft S (2010) Role of oxidative damage in toxicity of particulates. Free Rad Res J 44(1): 1-46.

10. Al-Salmi FA, Hamza RZ, El-Shenawy NS (2019) The interaction of zinc oxide/green tea extract complex nanoparticles and MSG in liver of rats. Current Pharmace. Biotechnol.20(6):465-475.

11. Zanchi MM, Vanusa M, Daniela DB, Laura MV, Cristiano CS, Melina BS, Aryele P I, Francielli WS (2015) Green tea infusion improves cyclophosphamide-induced damage on male mice reproductive system. Toxicology Reports 2:252-260.

Peer) reviewing PDF | (2019:04:36867:1:0:CHECK 21 Jun 2019) 
401

402

403

404

405

406

407

408

409

410

411

412

413

414

415

416

417

418

419

420

421

422

423

424

425

426

427

428

429

430

431

12. El-Shenawy NS, Hamza RZ, Al-Salmi FA, Al-Eisa RA (2019) Evaluation of nanoparticles zinc oxide/ camellia sinensis complex and monosodium glutamate in the kidney of rats: antioxidant and histological approaches .Curr Pharmace Biotechnol. In Press.

13. Agarwal H, Kumar SV, Rajeshkumar S (2017) A review on green synthesis of zinc oxide nanoparticles - An eco-friendly approach. Resource-Efficient Technology. 3(4):406-413

14. Heinlaan M, Ivask A, Blinova I, Dubourguier HC, Kahru A (2008). Toxicity of nanosized and bulk $\mathrm{ZnO}, \mathrm{CuO}$ and $\mathrm{TiO} 2$ to bacteria Vibrio fischeri and crustaceans Daphnia magna and Thamnocephalus platyurus. Chemosphere 71: 1308-1316.

15. Santhoshkumar J, Kumar SV, Rajeshkumar S. (2017). Synthesis of zinc oxide nanoparticles using plant leaf extract against urinary tract infection pathogen. Resource-Efficient Technol. 3: $459-465$.

16. Rajakumar G, Thiruvengadam M, Mydhili G, Gomathi T, and Chung IM (2018) Green approach for synthesis of zinc oxide nanoparticles from Andrographis paniculata leaf extract and evaluation of their antioxidant, anti-diabetic, and antiinflammatory activities. Bioprocess Biosystems Engin. 41(1): 21-30.

17. Krishnaraj C, Jagan E, Rajasekar S, Selvakumar P, Kalaichelvan P, Mohan N. Synthesis of silver nanoparticles using Acalypha indica leaf extracts and its antibacterial activity against water borne pathogens. Colloids Surf. B 76: 50-56 (2010)

18. Figueiroa MS, Vieira JSBC, Leite DS, et al. (2009) Green tea polyphenols inhibit testosterone production in rat Sertoli cells. Asian J Androl 11: 362-370.

19. Soussi A, Gaubin Y, Beau B, et al. (2006). Stress proteins (Hsp72/73, Grp94) expression pattern in rat organs following metavanadate administration. Effect of green tea drinking. Food Chem Toxicol 44:1031-1037.

20. Elhalwagy MEA, Darwish NS, Zaher EM. (2008) Prophylactic effect of green tea polyphenols against liver and kidney injury induced by fenitrothion insecticide. Pest Biochem Physiol 91:81-89.

21. Abshenas J, Babaei H, Zare M-H, Allahbakhshi A, Sharififar F (2011). The effects of green tea (Camellia sinensis) extract on mouse semen quality after scrotal heat stress. Veter Res Forum 2 (4): $242-247$

22. Mattson MP, (2008) Glutamate and neurotrophic factors in neuronal plasticity and disease. Ann N Y Acad Sci 1144:97-112. 
432

433

434

435

436

437

438

439

440

441

442

448

446

447

448

449

450

451

452

453

454

455

456

457

458

459

460

461

462

463

464

23. Onaolapo OJ, Onaolapo AY, Akanmu MA, Gbola O (2016). Evidence of alterations in brain structure and antioxidant status following 'low-dose' monosodium glutamate ingestion. Pathophysiol 23 (3): 147-156.

24. Narayanan SN, Kumar RS, Paval J, Nayak S. (2010). Effect of ascorbic acid on the monosodium glutamate-induced neurobehavioral changes in periadolescent rats. Bratisl Lek Listy 111(5):247-252.

25. Jhamandas K, Marien M (1987). Glutamate-evoked release of endogenous brain dopamine: inhibition by an excitatory amino acid antagonist and an enkephalin analogue. Br. J. Pharmac. 90:641- 650 .

26. Bertrand PP, Bertrand RL (2010). Serotonin release and uptake in the gastrointestinal tract.

\section{Auton Neurosci 153:47-57.}

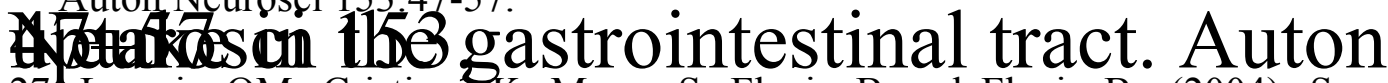

27. Laercio OM, Cristiane K, Maura S, Flavio B and Flavia B (2004). Serotonin reuptake inhibitors in auditory processing disorders in elderly patients. Laryngoscope 114(9): 6561659 .

28. Li Z, Van Aelst L, Cline HT. (2000) Rho GTPases regulate distinct aspects of dendritic arbor growth in Xenopus central neurons in vivo. Nat Neurosci 3:217-225.

29. Waterhouse EG, Xu B. (2009) New insights into the role of brain-derived neurotrophic factor in synaptic plasticity. Mol Cell Neurosci 42:81-89.

30. Cassiman D, Denef C, Desmet VJ, et al. (2001) Human and rat hepatic stellate cells express neurotrophins and neurotrophin receptors. Hepatol 33:148-58.

31. Matthews VB, Astrom MB, Chan MH, et al. (2009) Brain-derived neurotrophic factor is produced by skeletal muscle cells in response to contraction and enhances fat oxidation via activation of AMP-activated protein kinase. Diabetologia 52:1409-18.

32. Donovan MJ, Lin MI, Wiegn P, Ringstedt T, Kraemer R, Hahn R, Wang S, Ibañez CF, Rafii S, Hempstead BL (2000). Brain-derived neurotrophic factor is an endothelial cell survival factor required for intramyocardial vessel stabilization. Development 127(21):4531-4540.

33. Minghetti L (2004). Cyclooxygenase-2 (COX-2) in Inflammatory and Degenerative Brain Diseases. J Neuropathol Experim Neurol 63 (9): 901-910.

34. Magnotti RA, Eberly JP, McConnell RS (1988) Field measurement of plasma and erythrocyte cholinesterases, Clin Chim Acta 176: 315-32. 
465 35. Ciarlone AE (1978). Further modification of a fluorometric method for analyzing brain 466 amines. Microchem J 23:9-12.

467 35. Suzuki K, Ota H, Sasagawa S, Sakatani T, Fujikura T (1983). Assay method for 468 myeloperoxidase in human polymorphonuclear leukocytes. Anal Biochem 132:345-352.

469 36. Litwack G, Bothwell JW, Williams JN, Elvehjem CA (1953). A colorimetric assay for $470 \quad$ xanthine oxide in rat liver homogenates. J Biol Chem 200: 303-310.

471 37. Hu ML (1994). Measurement of protein thiol groups and glutathione in plasma. Methods in 472 Enzymology. 233:380-385

473 38. Veronesi B, Makwana O, Pooler M, Chen L (2005). Effects of subchronic exposures to 474 concentrated ambient particles. VII. Degeneration of dopaminergic neuron ApoE mice. Inhal 475 Toxicol 17: 235-241.

476 39. Onyema OO, Farombi EO, Emerole GO, Ukoha AI, Onyeze GO (2006) Effect of vitamin E 477 on monosodium glutamate induced hepatotoxicity and oxidative stress in rats. Indian $\mathrm{J}$ 478 Biochem Biophys 43: 20-24.

479 40. Zanfirescu A, Cristea AN, Nitulescu GM, Velescu BS, Gradinaru D (2018). Chronic 480 monosodium glutamate administration induced hyperalgesia in mice. nutrients. $21 ; 10(1)$. pii: $481 \quad$ E1. doi: 10.3390/nu10010001.

482 41. Hamza RZ, Al-Harbi MS (2014) Monosodium glutamate induced testicular toxicity and the 483 484 485 486 possible ameliorative role of vitamin E or selenium in male rats. Toxicol Rep 22(1):10371045.

42. Gebicki JM (2016) Oxidative stress, free radicals and protein peroxides. Arch Biochem Biophys 595: 33-39.

43. Umukoro S, Oluwole G, Olamijowon H, Omogbiya A, Eduviere A (2015) Effect of monosodium glutamate on Behavioral phenotypes, biomarkers of oxidative stress in brain tissues and liver enzymes in mice. Biomed Life Sci 5(5):339-349.

44. Paul MV, Abhilash M, Varghese MV, Alex M, Nair RH. (2012) Protective effects of alphatocopherol against oxidative stress related to nephrotoxicity by monosodium glutamate in rats. Toxicol Mech Methods 22(8):625-630.

45. Shivasharan BD, Nagakannan P, Thippeswamy BS, Veerapur VP. (2013) Protective Effect of Calendula officinalis L. Flowers Against Monosodium Glutamate-Induced Oxidative Stress and Excitotoxic Brain Damage in Rats. Indian J Clin Biochem 28(3):292-298. 
496

497

498

499

500

501

502

503

504

505

506

507

508

509

510

511

512

513

514

515

516

517

518

519

520

521

522

523

524

525

526

46. Mishra A, Goel RK (2013) Psychoneurochemical investigations to reveal neurobiology of memory deficit in epilepsy. Neurochem Res 38: 2503-2515.

47. Izquierdo I, Medina JH (1997) Memory formation: the sequence of biochemical events in the hippocampus and its connection to activity in other brain structures. Neurobiol Learn Mem 68: 285-316.

48. Ramos-Rodriguez JJ, Molina-Gil S, Rey-Brea R, Berrocoso E, Garcia-Alloza M. (2013). Specific serotonergic denervation affects tau pathology and cognition without altering senile plaques deposition in APP/PS1 mice. PLoS One 21;8(11):e79947. doi:10.1371/journal.pone.0079947.

49. Hashem HE, El-Din Safwat MD, Algaidi S (2012) The effect of monosodium glutamate on the cerebellar cortex of male albino rats and the protective role of vitamin $\mathrm{C}$ (histological and immunohistochemical study). J Mol Histol 43(2):179-186.

50. Kardeşler A, Başkale E (2017). Investigation of behavioral and neurochemical effects of monosodium glutamate on the neonatal rats. https://www.researchgate.net/publication/316037980

51. Tao T, Zhao M, Yang W, Bo Y, Li W. Neuroprotective effects of therapeutic hypercapnia on spatial memory and sensorimotor impairment via anti-apoptotic mechanisms after focal cerebral ischemia/reperfusion. Neurosci Lett 2014; 573: 1-6.

52. Madrigal JL, Moro MA, Lizasoain I, Lorenzo P, Fernández AP, Rodrigo J, Boscá L, Leza JC. (2003). Induction of cyclooxygenase-2 accounts for restraint stress-induced oxidative status in rat brain. Neuropsychopharmacol 28(9):1579-88.

53. Bazan NG. (2003). Synaptic lipid signaling: Significance of polyunsaturated fatty acids and platelet-activating factor. J Lipid Res 44: 2221-33

54. Wang B, Feng W, Wang M, Wang T, Gu Y, Zhu M, Ouyang H, Shi J, Zhang F, Zhao Y (2008). Acute toxicological impact of nano- and submicro-scaled zinc oxide powder on healthy adult mice. J Nanopart Res 10: 263-276.

55. Zheng Y, Li R, Wang Y (2009). In vitro and in vivo biocompatibility of ZnO nanoparticles. Int J Mod Phys B 23: 1566-1571.

56. Win-Shwe T, Fujimaki H (2011). Nanoparticles and neurotoxicity. Int J Mol Sci 12: 62676280.

57. Gantedi S, Anreddy RNR (2012). Toxicological studies of zinc oxide nanomaterials in rats, Toxicol Environ Chem 94(9): 1768-1779. 
527

528

529

530

531

532

533

534

535

536

537

538

539

540

541

542

543

544

545

546

547

548

549

550

551

552

553

554

555

556

557

558

559

560

561

58. Elshama S, El-Kenawy AE, Osman HH (2017). Histopathological study of zinc oxide nanoparticle-induced neurotoxicity in rats. Current Topic Toxicol 13: 95-103.

\section{The figure legends}

Fig.1: Scanning Electron Microscopy (SEM) Analysis showing the morphology of the prepared $\mathrm{ZnO}$ nanoparticles loaded with green tea extract was examined using scanning electron microscopy. Fig. 1a; showing two views of the surface morphology of the $\mathrm{ZnO}$ nanoparticles complexes with green tea. The SEM image showed that most of the $\mathrm{ZnO}$ nanoparticles showed a homogeneous distribution in shape. Fig. 1b; Energy Dispersive X-Ray Diffractive (EDX) Analysis showing the chemical compositions of the zinc oxide/green tea complex was determined using energy-dispersive X-ray diffraction (EDX).

Fig. 2: Activities of superoxide dismutase and catalase in the brain rats treated with different doses of monosodium glutamate (MSG), zinc oxide nanoparticles ( $\mathrm{ZnO} N P s$ ), green tea extract (GTE), and ZnO NPs / GTE. Values are presented as the mean \pm S.E. ${ }^{\mathrm{a}} P<0.05$ vs. control and ${ }^{\mathrm{b}}$ $P<0.05$ vs. its relative group of MSG.

Fig. 3: Glutathione peroxidase (GPx) activity and glutathione (GSH) levels in the brain rats treated with different doses of monosodium glutamate (MSG), zinc oxide nanoparticles ( $\mathrm{ZnO}$ NPs), green tea extract (GTE), and ZnO NPs / GTE. Values are presented as the mean \pm S.E. ${ }^{\text {a }}$ $P<0.05$ vs. control and ${ }^{\mathrm{b}} P<0.05$ vs. its relative group of MSG.

Fig. 4: Activities of myeloperoxidase and xanthine oxidase in the brain rats treated with different doses of monosodium glutamate (MSG), zinc oxide nanoparticles ( $\mathrm{ZnO} \mathrm{NPs),} \mathrm{green} \mathrm{tea} \mathrm{extract}$ (GTE), and ZnO NPs / GTE. Values are presented as the mean \pm S.E. ${ }^{\mathrm{a}} P<0.05$ vs. control and ${ }^{\mathrm{b}}$ $P<0.05$ vs. its relative group of MSG.

Fig. 5: Brain-derived neurotrophic factor (BDNF) in the brain rats treated with different doses of monosodium glutamate (MSG), zinc oxide nanoparticles (ZnO NPs), green tea extract (GTE), and ZnO NPs / GTE. Values are presented as the mean \pm S.E. ${ }^{a} P<0.05$ vs. control and ${ }^{b} P<$ 0.05 vs. its relative group of MSG.

Fig. 6: Cyclooxygenase-2 (COX-2) activity in the brain rats treated with different doses of monosodium glutamate (MSG), zinc oxide nanoparticles (ZnO NPs), green tea extract (GTE), and ZnO NPs / GTE. Values are presented as the mean \pm S.E. ${ }^{\text {a }} P<0.05 v s$. control and ${ }^{\mathrm{b}} P<$ 0.05 vs. its relative group of MSG.

Fig. 7: Prostaglandin E2 (PGE2) level in the brain rats treated with different doses of monosodium glutamate (MSG), zinc oxide nanoparticles (ZnO NPs), green tea extract (GTE), and ZnO NPs / GTE. Values are presented as the mean \pm S.E. ${ }^{a} P<0.05$ vs. control and ${ }^{\mathrm{b}} P<$ 0.05 vs. its relative group of MSG. 
562 Fig. 8: Histopathological slides of the brain stained with hematoxylin and eosin in (A) control 563 groups of rat showing normal arrangement of layers of neurons (Blue arrow) and neuronal fibers $564\left(^{*}\right)$ (400X); (B) cross section of rat brain treated with ZnO NPs showing normal structure 565 (100X). (C) the cross section showed the animals that treated with green tea extract with normal 566 nerve cell (400X); (D) cross section of rat brain treated with ZnONPs/green tea $(10 \mathrm{mg} / \mathrm{Kg}$ ) 567 showing normal white matter with normal neurons (Blue arrow) and neuronal fibers $(*)(400 \mathrm{X})$; 568 (E) (MSG-LD) treated-group $(75 \mathrm{mg} / \mathrm{kg}$ ) showing moderate area of necrosis $(* * *)$ in the brain 569 (400X); (F) (MSG- HD) treated-group $(150 \mathrm{mg} / \mathrm{kg})$ showing disorganized pyramidal cells $(*)$ 570 and some swelling in the brain cells (***) (400X); (G) The MSG-LD and ZnONPs/green tea 571 complex showing very reduced congested area $(*)$ with normal neural fibers (Yellow arrow ) 572 (100X); $(\mathrm{H})$ the MSG-HD and $\mathrm{ZnONPs} /$ green tea complex showing the recovery of the 573 congested area with scattered few apoptotic cells $\left({ }^{* *}\right)$ with appearance of dark stained nuclei $574(* *)$ and reduced necrotic neurons (100X).

575 
Table $\mathbf{1}$ (on next page)

Table 1 
Table 1: Effect of ZnO NPs / GTE mixture on the dopamine, serotonin, catecholamine, acetylcholinesterase and thiol of brain's tissue of

2 rats previously exposed to MSG.

3

\begin{tabular}{|c|c|c|c|c|c|c|c|c|}
\hline Parameters & Control & MSG-LD & MSG-HD & ZnO NPs & GTE & $\begin{array}{c}\text { ZnO } \\
\text { NPs/GTE }\end{array}$ & $\begin{array}{c}\text { MSG-LD + } \\
\text { ZnO } \\
\text { NPs/GTE }\end{array}$ & $\begin{array}{c}\text { MSG-HD + } \\
\text { ZnO NPs/GTE }\end{array}$ \\
\hline $\begin{array}{l}\text { Dopamine (DA) } \\
(\mu \mathrm{g} / \mathrm{mL})\end{array}$ & $1.6 \pm 0.2$ & $1.7 \pm 0.2$ & $0.8 \pm 0.1^{\mathrm{a}}$ & $1.5 \pm 0.1$ & $1.6 \pm 0.1$ & $1.9 \pm 0.1$ & $1.3 \pm 0.1$ & $1.1 \pm 0.1^{b}$ \\
\hline $\begin{array}{l}\text { Serotonin }(5-\mathrm{HT}) \\
(\mu \mathrm{g} / \mathrm{mL})\end{array}$ & $0.7 \pm 0.1$ & $0.8 \pm 0.1$ & $0.4 \pm 0.1^{\mathrm{a}}$ & $0.6 \pm 0.1$ & $0.6 \pm 0.1$ & $0.7 \pm 0.1$ & $0.6 \pm 0.1$ & $0.6 \pm 0.1$ \\
\hline $\begin{array}{l}\text { Epinephrine }(\mu \mathrm{g} / \\
\mathrm{mL})\end{array}$ & $0.9 \pm 0.1$ & $1.0 \pm 0.1$ & $0.6 \pm 0.1^{\mathrm{a}}$ & $0.8 \pm 0.1$ & $0.8 \pm 0.1$ & $0.9 \pm 0.1$ & $0.8 \pm 0.1$ & $0.8 \pm 0.1^{b}$ \\
\hline $\begin{array}{l}\text { Nor- epinephrine } \\
(\mu \mathrm{g} / \mathrm{mL})\end{array}$ & $0.8 \pm 0.1$ & $0.8 \pm 0.1$ & $0.4 \pm 0.1^{\mathrm{a}}$ & $0.7 \pm 0.1$ & $0.8 \pm 0.1$ & $0.8 \pm 0.1$ & $0.7 \pm 0.1$ & $0.6 \pm 0.1^{b}$ \\
\hline $\begin{array}{l}\text { Acetylcholinesterase } \\
(\mathrm{mmol} / \mathrm{min} / \mathrm{mL})\end{array}$ & $592.1 \pm 22.9$ & $607.8 \pm 14.1$ & $382.2 \pm 27.2^{\mathrm{a}}$ & $564.4 \pm 17.3$ & $564.7 \pm 15.8$ & $626.4 \pm 10.1$ & $573.4 \pm 22.2^{b}$ & $467.1 \pm 11.6^{b}$ \\
\hline Thiol level & $11.5 \pm 0.9$ & $11.8 \pm 1.4$ & $6.2 \pm 1.4^{\mathrm{a}}$ & $13.8 \pm 0.8^{\mathrm{a}}$ & $11.6 \pm 0.8$ & $11.1 \pm 1.0$ & $12.2 \pm 1.6$ & $10.1 \pm 1.7^{b}$ \\
\hline
\end{tabular}

4 Values are expressed as mean \pm SE, $n=8$. MSG- LD; the lower dose of monosodium glutamate, and MSG-HD; the higher dose of monosodium

5 glutamate, $\mathrm{ZnO}$ NPs; zinc oxide nanoparticles, GTE; green tea extract. ${ }^{a}$ Significant difference as compared to control, and ${ }^{\mathrm{b}}$ significant difference

6 as compared to its relative group of $\mathrm{MSG}(P \leq 0.05)$. 
Figure 1 (on next page)

Scanning Electron Microscopy (SEM) Analysis showing the morphology of the prepared ZnO nanoparticles 


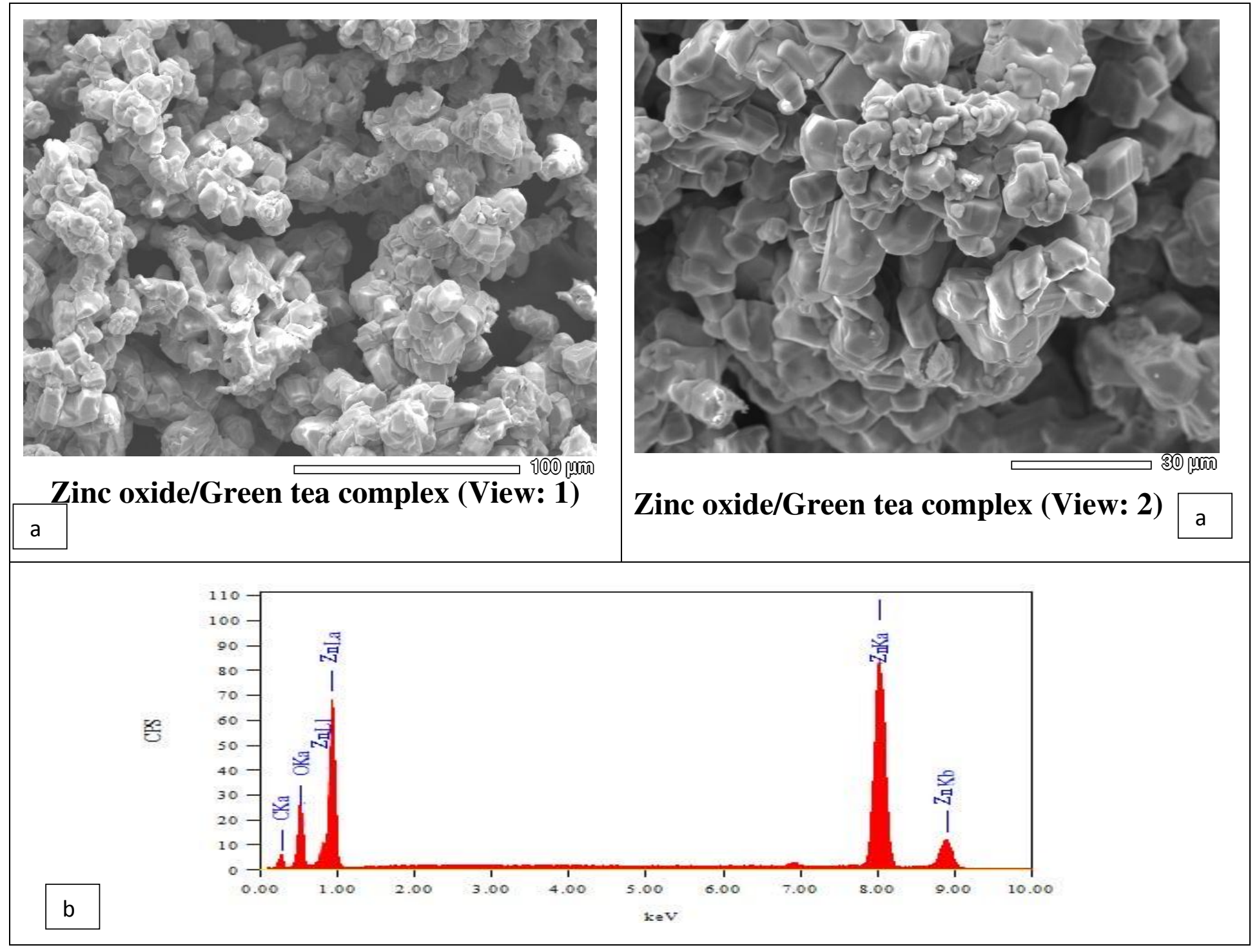

Fig.1: Scanning Electron Microscopy (SEM) Analysis showing the morphology of the prepared $\mathrm{ZnO}$ nanoparticles loaded with green tea extract was examined using scanning electron microscopy. Fig. 1a; showing two views of the surface morphology of the $\mathrm{ZnO}$ nanoparticles complexes with green tea. The SEM image showed that most of the $\mathrm{ZnO}$ nanoparticles showed a homogeneous distribution in shape .Fig. 1b; Energy Dispersive X-Ray Diffractive (EDX) Analysis showing the chemical compositions of the zinc oxide/green tea complex was determined using energy-dispersive X-ray diffraction (EDX). 
Figure 2 (on next page)

Activities of superoxide dismutase and catalase in the brain rats treated with different doses of monosodium glutamate (MSG), zinc oxide nanoparticles (ZnO NPs), green tea extract (GTE), and ZnO NPs / GTE. 


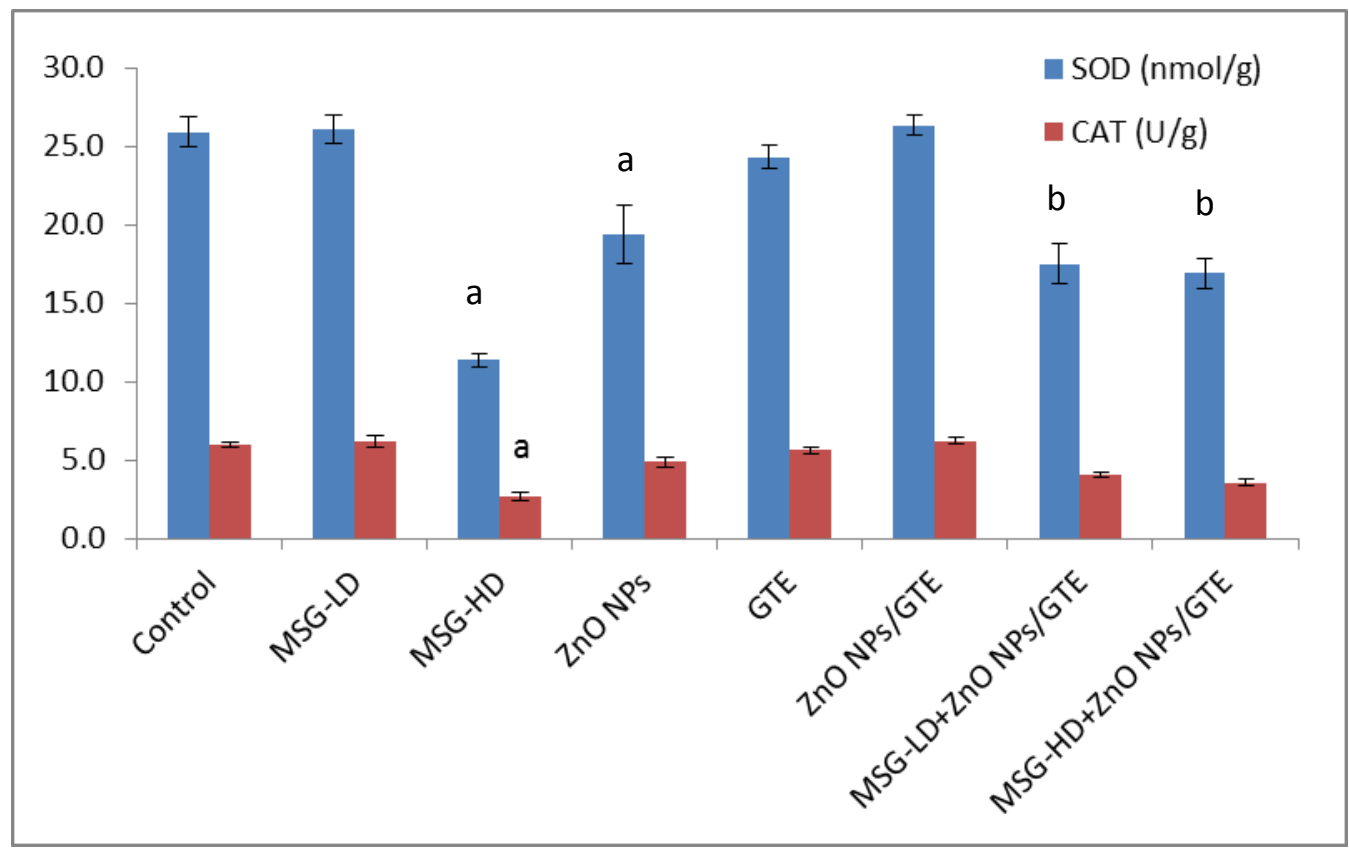

Fig. 2: Activities of superoxide dismutase and catalase in the brain rats treated with different doses of monosodium glutamate (MSG), zinc oxide nanoparticles ( $\mathrm{ZnO} \mathrm{NPs),} \mathrm{green} \mathrm{tea} \mathrm{extract}$ (GTE), and ZnO NPs / GTE. Values are presented as the mean \pm S.E. ${ }^{a} P<0.05$ vs. control and ${ }^{\mathrm{b}}$ $P<0.05 v s$. its relative group of MSG. 
Figure 3 (on next page)

Glutathione peroxidase (GPx) activity and glutathione (GSH) levels in the brain rats 


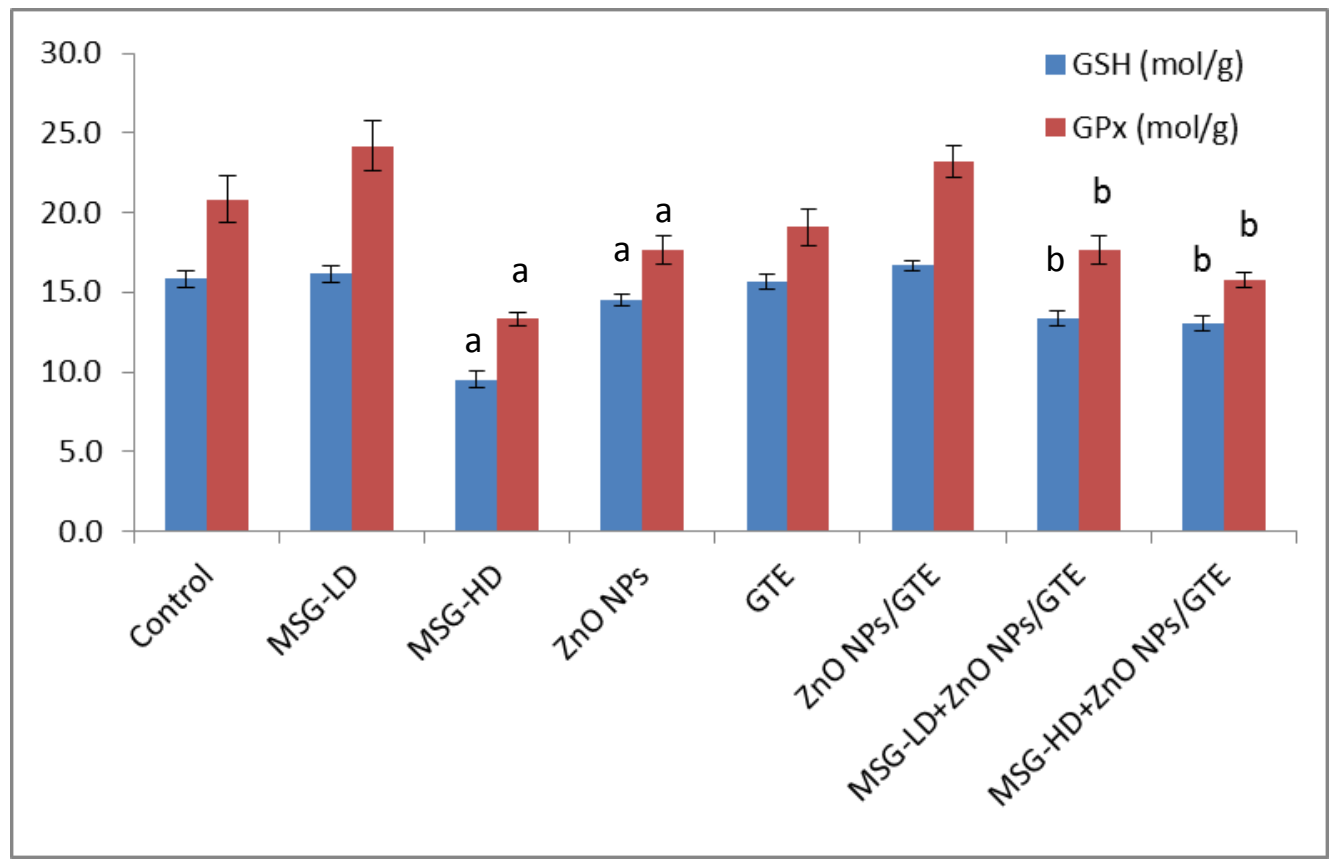

Fig. 3: Glutathione peroxidase (GPx) activity and glutathione (GSH) levels in the brain rats treated with different doses of monosodium glutamate (MSG), zinc oxide nanoparticles ( $\mathrm{ZnO}$ NPs), green tea extract (GTE), and ZnO NPs / GTE. Values are presented as the mean \pm S.E. ${ }^{\text {a }}$ $P<0.05$ vs. control and ${ }^{\mathrm{b}} P<0.05$ vs. its relative group of MSG. 
Figure 4 (on next page)

Activities of myeloperoxidase and xanthine oxidase in the brain rats 


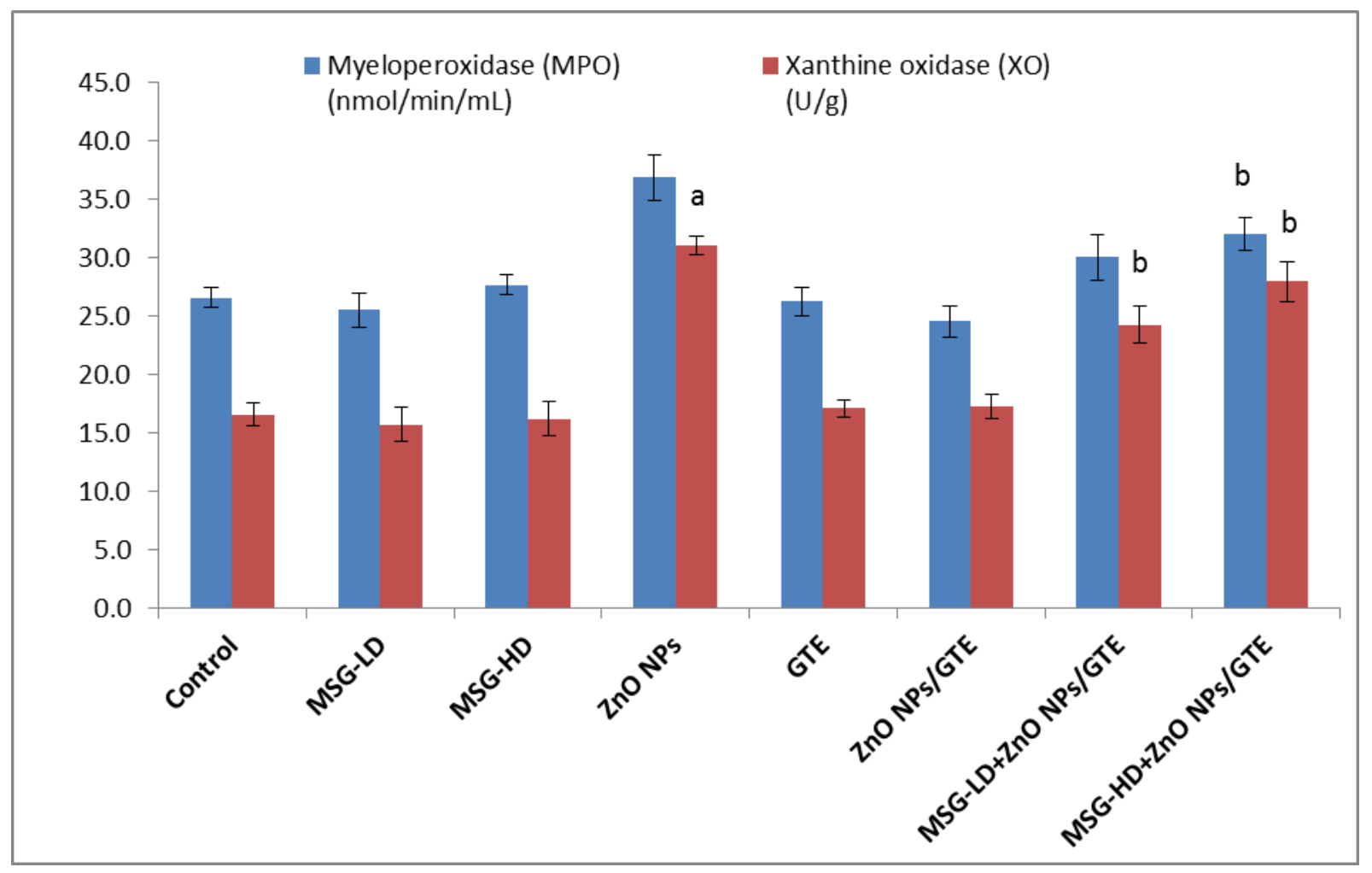

Fig. 4: Activities of myeloperoxidase and xanthine oxidase in the brain rats treated with different doses of monosodium glutamate (MSG), zinc oxide nanoparticles (ZnO NPs), green tea extract (GTE), and ZnO NPs / GTE. Values are presented as the mean \pm S.E. ${ }^{a} P<0.05$ vs. control and ${ }^{\mathrm{b}}$ $P<0.05$ vs. its relative group of MSG. 
Figure $\mathbf{5}$ (on next page)

Brain derived neurotrophic factor (BDNF) in the brain rats 


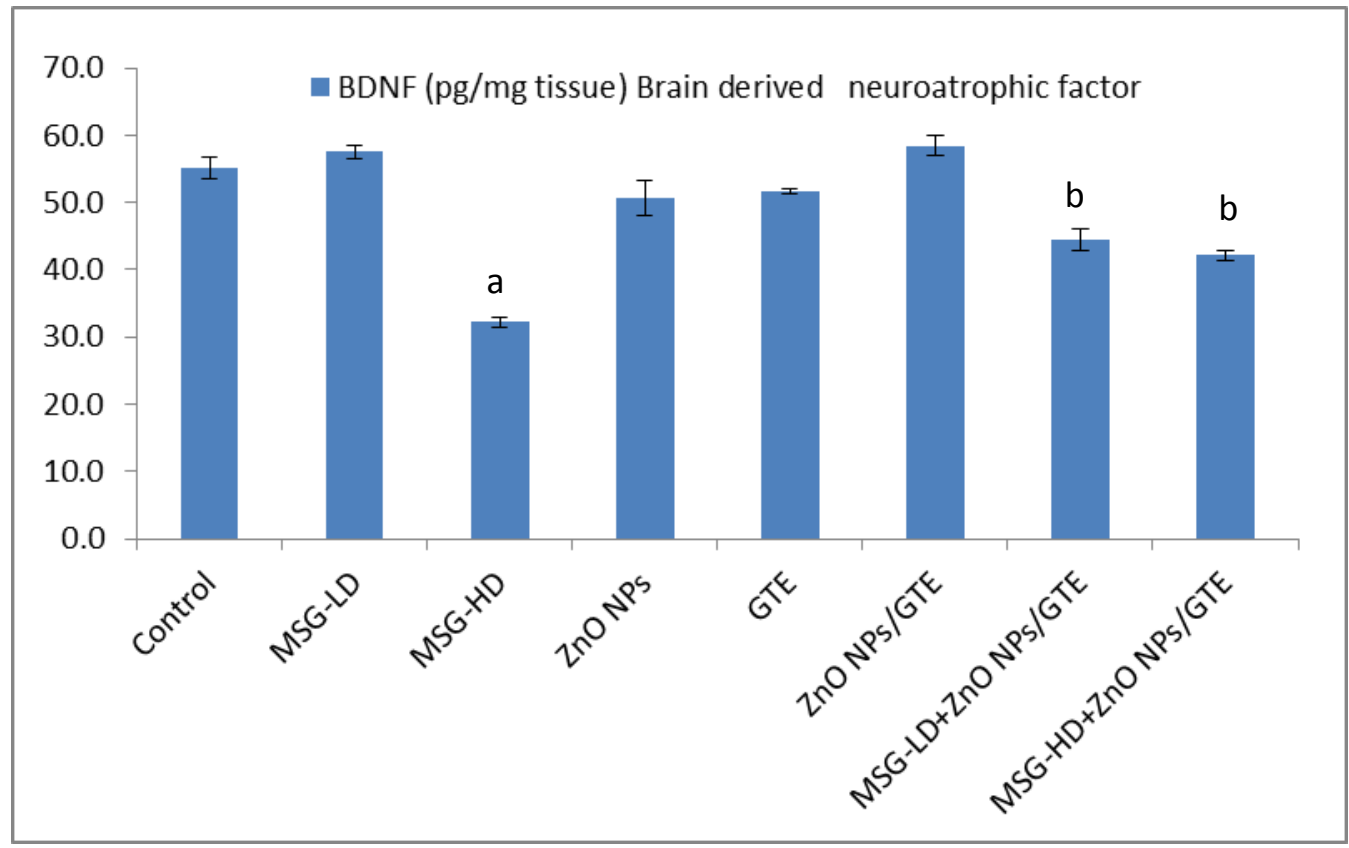

Fig. 5: Brain derived neurotrophic factor (BDNF) in the brain rats treated with different doses of monosodium glutamate (MSG), zinc oxide nanoparticles (ZnO NPs), green tea extract (GTE), and ZnO NPs / GTE. Values are presented as the mean \pm S.E. ${ }^{\mathrm{a}} P<0.05$ vs. control and ${ }^{\mathrm{b}} P<$ 0.05 vs. its relative group of MSG. 
Figure 6 (on next page)

Cyclooxygenase-2 (COX-2) activity in the brain rats 


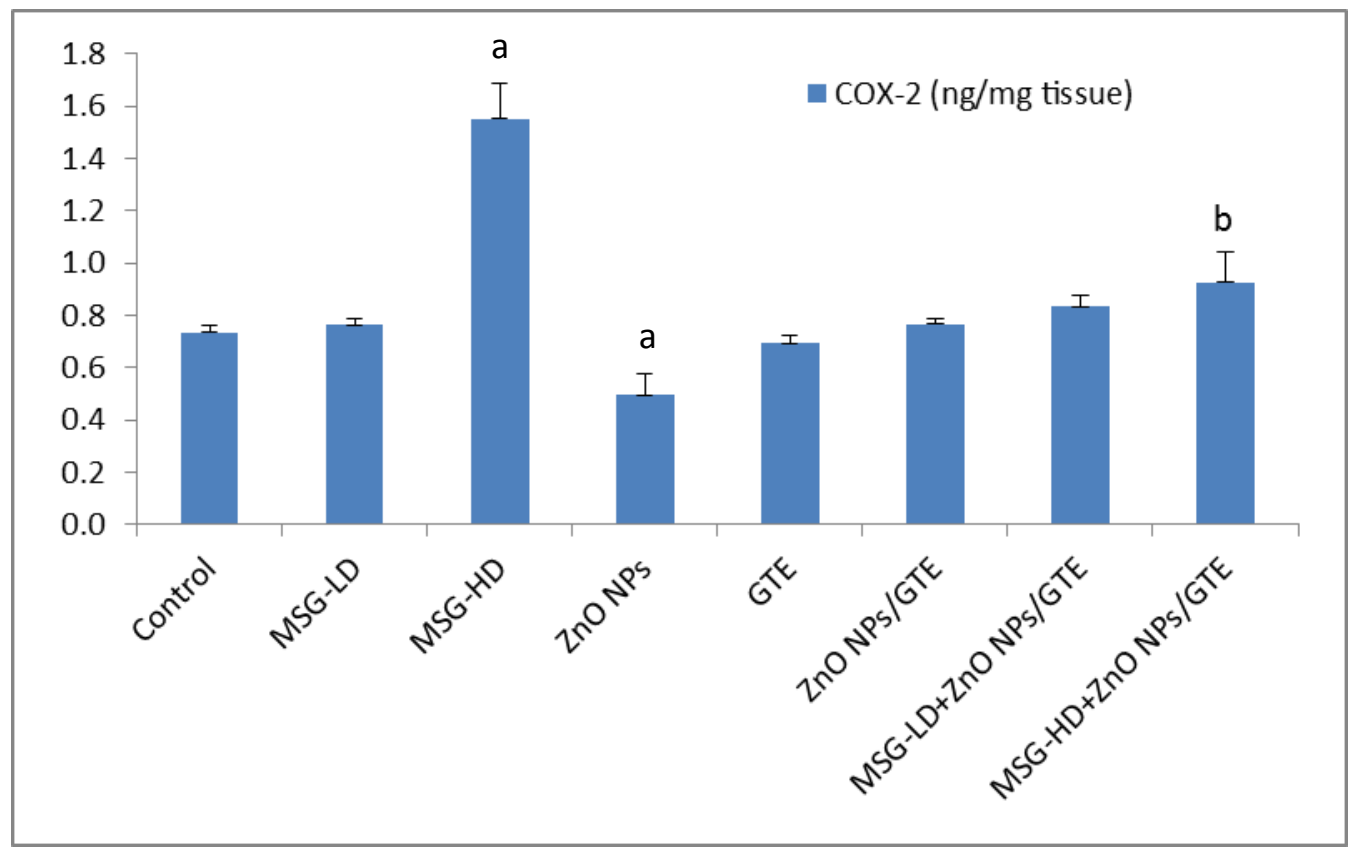

Fig. 6: Cyclooxygenase-2 (COX-2) activity in the brain rats treated with different doses of monosodium glutamate (MSG), zinc oxide nanoparticles (ZnO NPs), green tea extract (GTE), and ZnO NPs / GTE. Values are presented as the mean \pm S.E. ${ }^{\mathrm{a}} P<0.05$ vs. control and ${ }^{\mathrm{b}} P<$ $0.05 v s$. its relative group of MSG. 
Figure 7 (on next page)

Prostaglandin E2 (PGE2) level in the brain rats 


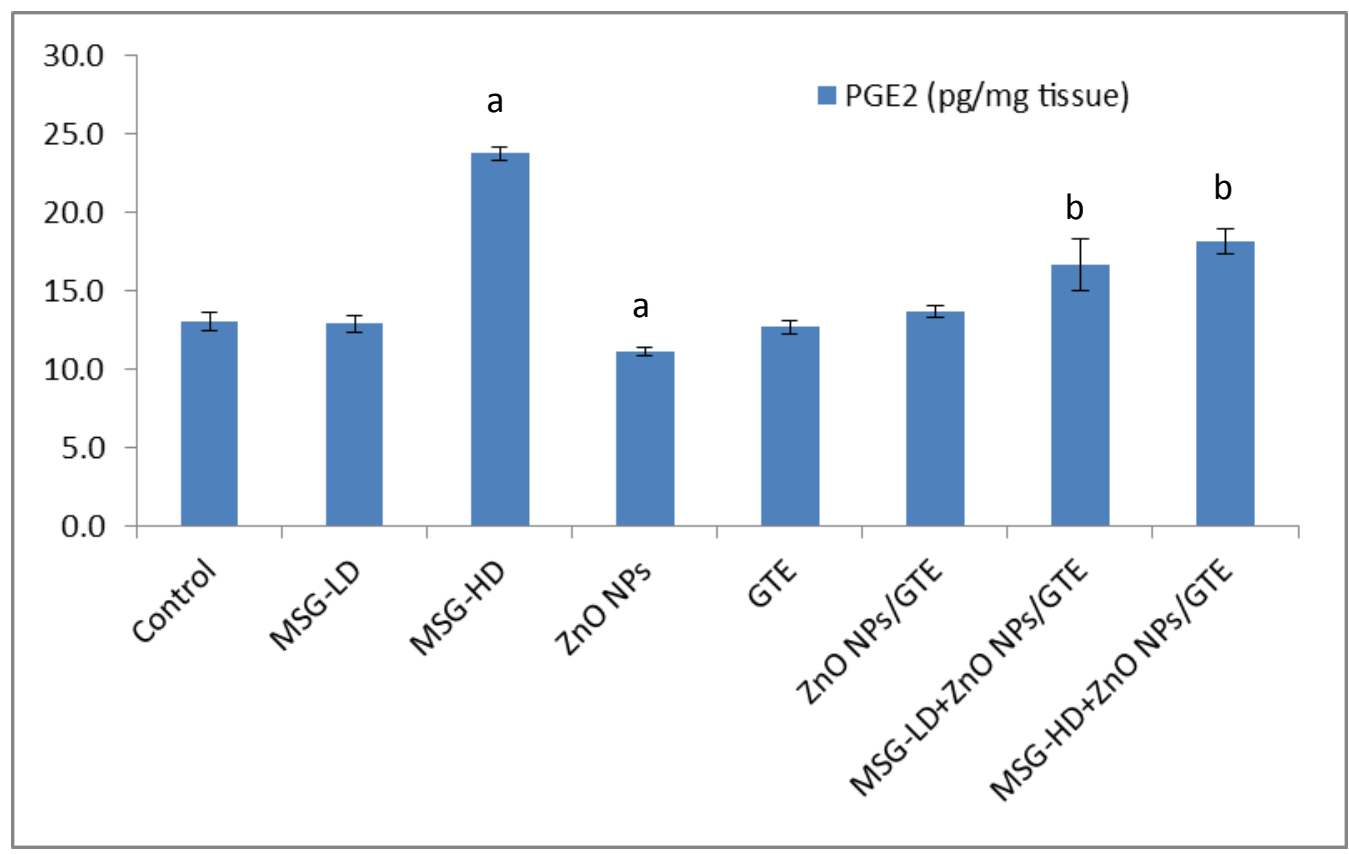

Fig. 7: Prostaglandin E2 (PGE2) level in the brain rats treated with different doses of monosodium glutamate (MSG), zinc oxide nanoparticles (ZnO NPs), green tea extract (GTE), and ZnO NPs / GTE. Values are presented as the mean \pm S.E. ${ }^{a} P<0.05 v s$. control and ${ }^{\mathrm{b}} P<$ 0.05 vs. its relative group of MSG. 
Figure 8 (on next page)

Histopathological sections 

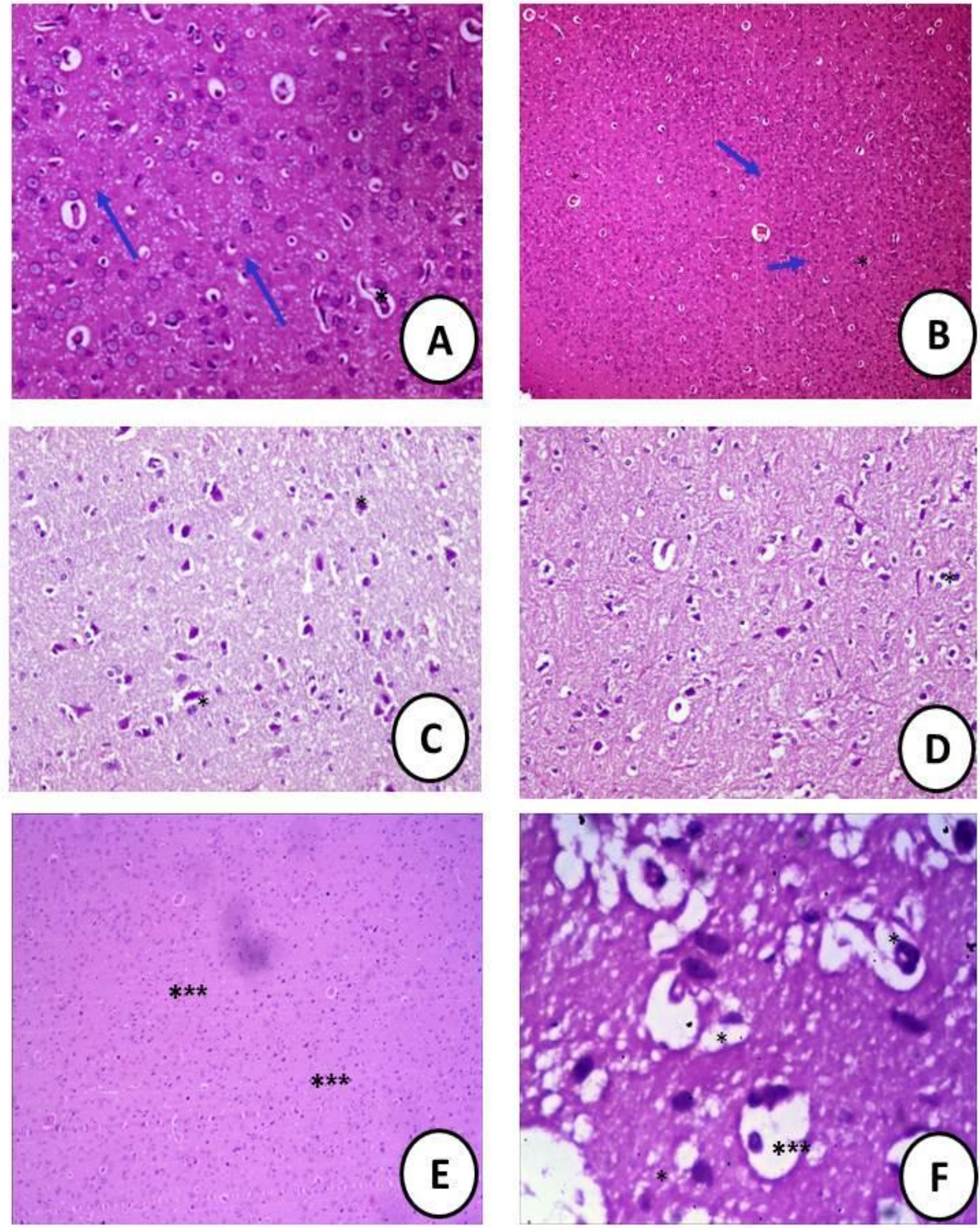

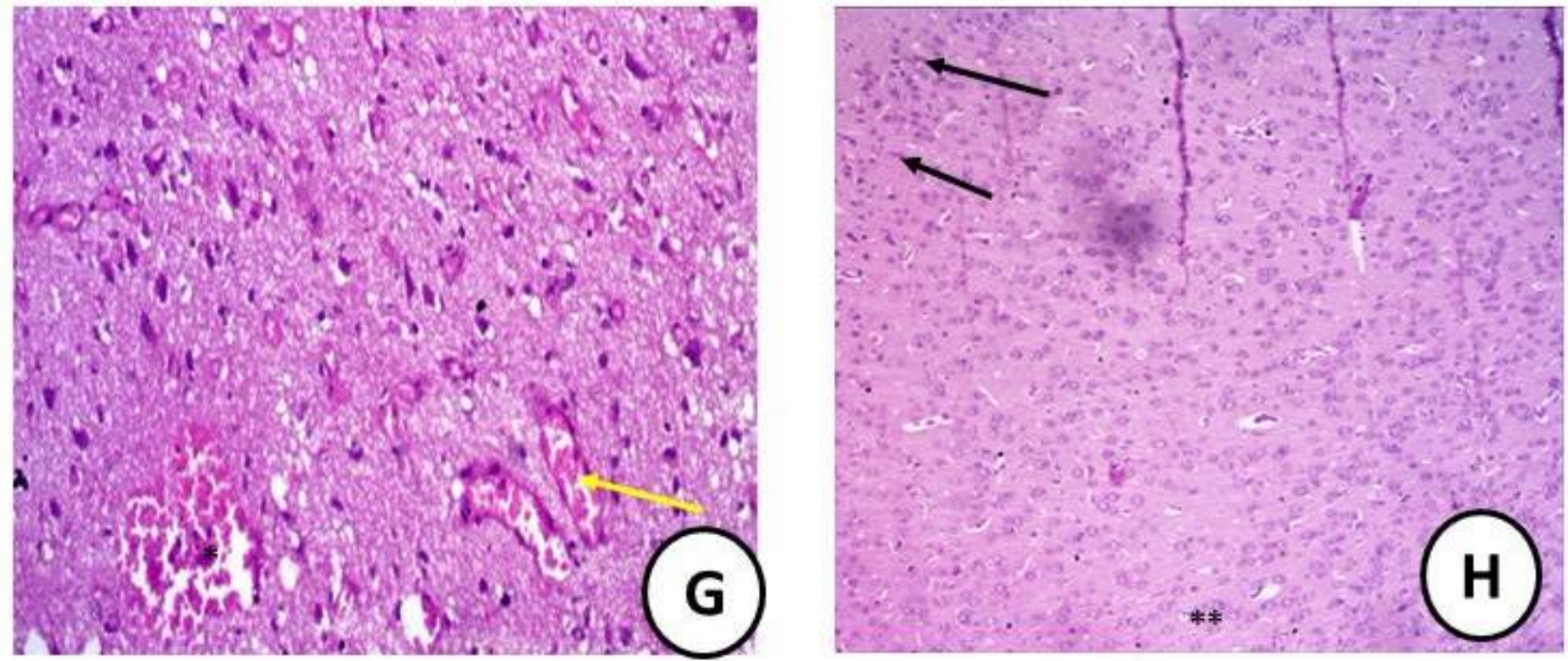

Fig. 8: Histopathological slides of the brain stained with hematoxylin and eosin in (A) control groups of rat showing normal arrangement of layers of neurons (Blue arrow) and neuronal fibers (*) (400X); (B) cross section of rat brain treated with ZnO NPs showing normal structure (100X). (C) the cross section showed the animals that treated with green tea extract with normal nerve cell (400X); (D) cross section of rat brain treated with $\mathrm{ZnONPs} /$ green tea $(10 \mathrm{mg} / \mathrm{Kg})$ showing normal white matter with normal neurons (Blue arrow) and neuronal fibers (*) (400X); (E) (MSG-LD) treated-group (75 mg/kg) showing moderate area of necrosis (***) in the brain (400X); (F) (MSG- HD) treated-group (150 mg/kg) showing disorganized pyramidal cells $\left(^{*}\right)$ and some swelling in the brain cells $(* * *)(400 \mathrm{X}) ;(\mathrm{G})$ The MSG-LD and $\mathrm{ZnONPs/green} \mathrm{tea} \mathrm{complex} \mathrm{showing} \mathrm{very} \mathrm{reduced} \mathrm{congested} \mathrm{area}\left(^{*}\right)$ with normal neural fibers (Yellow arrow ) (100X); (H) the MSG-HD and ZnONPs/green tea complex showing the recovery of the congested area with scattered few apoptotic cells $(* *)$ with appearance of dark stained nuclei $(* *)$ and reduced necrotic neurons (100X). 